\title{
On the legitimacy of Emergentism and Chaos complexity theory as conceivable challenges to the nativist paradigm
}

\author{
Mirzaee, Sepideh $\bowtie$ \\ Department of English, Mashhad Branch, Islamic Azad University, Mashhad, Iran (spdmirzaee@gmail.com) \\ Ghanizadeh, Afsaneh \\ Department of English, Mashhad Branch, Islamic Azad University, Mashhad, Iran \\ (ghanizadeafsane@yahoo.com)
}

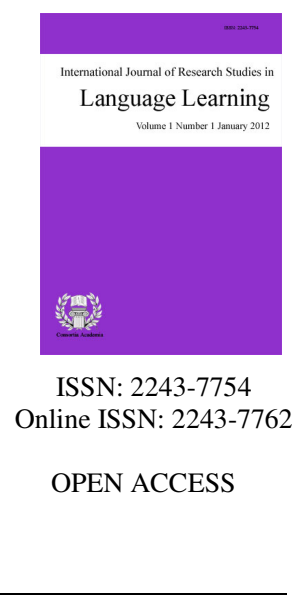

\section{Abstract}

Given that Emergentism is convincingly a novel challenge in the field of applied linguistics and is hotly under debate nowadays, its proponents especially Nick Ellis and his colleagues advocate it as a main alternative to the assumptions of Universal Grammar (UG) proposed by Noam Chomsky. As its main tenet, a plethora of contemporary emergentist research contend that language acquisition can be abridged to the use of simple learning strategies to pull out statistical regularities present in regular linguistic input which is exactly harmonious with what chaos, complexity scholars believe in considering the features of chaotic complex systems. In fact, emergentist scholars believe that knowledge of language is shaped in response to opportunities to interpret and/or form utterances in the course of communication. Therefore, Emergentism is an obvious challenge to UG as it disputes some of its major assumptions. In compliance with Emergentism and chaos complexity theory, the present paper tries to illustrate the implausibility of Chomskian account of language acquisition in terms of UG. What's more, the present paper sheds light on those aspects of language in which the Chomskian nativist paradigm fails to account including the explanatory adequacy of those cases and the reasons why both Emergentism and Chaos complexity theory are in dominant positions.

Keywords: complexity theory; Chomskian nativism; Universal grammar; nativist emergentist; empiricist emergentist 


\section{On the legitimacy of Emergentism and chaos complexity theory as conceivable challenges to the nativist paradigm}

\section{Introduction}

To have a more comprehensible view of Emergentism in the field of SLA, it is worthwhile to pinpoint the emergentist position among other SLA theories. In this regard, four extensive theoretical schools in the field of applied linguistics are proposed by Norris and Ortega (2003) based on the epistemology underlying various theoretical schools:

Linguistically-oriented theories based on UG (White, 2003)

$>\quad$ Interactionist theories such as Long (1996) interaction hypothesis which believed in acquisition as the result of the association between learner internal and external processes.

$>$ Sociocultural theory based on Vygotsky's argument in which he believes that all higher forms of learning are mediated in the course of culturally determined social interaction (Lantolf, 2005).

$>\quad$ And now

$>$ Emergentists theories, in which language learning is regarded as similar to any other type of learning, by considering the role of input that fine tunes the networked connections (Ellis, 1998).

Regarding the differences among emergentist view of language learning and other SLA theories, Ellis (2008) notes that Emergentism is completely different from both generativist and interactionist epistemologies. On the one hand, it is unable to get along with generative SLA since Emergentism denies symbolism, modularity, and innatism, and in fact, it removes linguistics from the center of the research domain, replacing it with the cognitive architecture. On the other hand, regardless of the common interest in functionalist explanations and cognitive constructs, emergentist theory shares little resemblance with interactionist SLA. Factors such as remarkably specialized neurobiological treatment of cognitive processes, the lack of a traditional dichotomy between representation and access, and the absence of interest in non-cognitive variables all differentiate emergentist from interactionist points of view. It is worth highlighting that until recently generativist and interactionist theories encompassed the SLA research mainstream. However, Ellis (2008) asserts, the 1990s brought two new types of theories into the view, with exclusive epistemologies: sociocultural theory (SCT) and Emergentism.

\subsection{Significance of the study}

Until recently there have been growing lists of advocates who join either Emergentism or nativism as two opposing ends of the continuum of second language acquisition theories. What has to be brought into consideration is that up to the present time a plethora of articles based on each of these theories were written by different scholars who are pioneers in each of them. Since nativism pioneered by Noam Chomsky and empiricist Emergentism, advocated by Nick Ellis, are contradictory in many respects, scholars are engaging in criticizing each other every time. This paper aims at specifying the exact nature of those areas in the two theories which are in contrast with each other. Worth considering is that this paper is in line with emergentists and chaos complexity theorists. As a result, first a short recount of the general literature about Emergentism and complexity theory is provided and then some pieces of evidence as legitimate and rightful rationales are considered in order to demonstrate that nativism cannot be regarded as an appropriate basis for second language acquisition. 


\section{Literature review}

A good account of Emergentism has been put forward by William O' Grady, an associate professor of linguistics in Calgary University. He states that the roots of Emergentism can be traced to the work of Mill (1930), who proposed that a system can have some components. The interaction among these components can result in more than the sum of its parts. As Mill observes, conspicuous examples of this come from chemistry. For example, the chemical amalgamation of two substances creates a third substance with properties different from those of either of the two substances discretely, or both of them taken together. All can observe that none of the features of hydrogen or oxygen is visible in those of their fusion; water (O'Grady, 2003).

Based on the literature, there are two main subcategories of the Emergentism. The 'Nativist' Emergentists which mostly relates to the work of O' Grady $(2003,2005,2008)$ and the 'Empiricist' Emergentists, which is the focus of present paper, are typically included in the work of Nick Ellis and his colleagues (Ellis, 1998, 2001, 2002, 2005, 2008). It is worthy of note that Empiricist Emergentism is also referred to as mainstream Emergentism (O' Grady, 2003). Also, it is worthwhile mentioning that you may see many different types of Emergentisms under different names such as input-based emegentism, processor based emrgentism (O' Grady, 2008), but the main focus here, as mentioned above, is the empiricist emergnetism advocated by N. Ellis and his associates.

\subsection{Nativist Emergentism vs. empiricist Emergentism}

We have previously noted that Emergentist approaches to language acquisition can be regarded as two main types. But since the present paper is not in charge of explaining nativist Emergentism, hence we are going to be as concise as possible in explaining these two types along with each other in this section in order to make the difference between them more apparent. According to O'Grady, Lee, and Kwak (2009) on the one hand, there is a massive body of research that concentrates on the crucial role of input in order to comprehend how language acquisition takes place. On the other hand, there is a minor body of research which demonstrates the role of working memory interface as the processor in language acquisition, considering problems of learnability that have conventionally been the special domain of UG-based work.

O'Grady (2003) was regarded as an advocate of the latter approach. In fact and as O'Grady maintains in many of his articles he believes in nativist emregentism as nativism without universal grammar. In other words, he only believes in UG parameters and not principles. This approach is sometimes referred to as processor based approach. Nick Ellis (2008) who is the pioneer of the empiricist Emergentism considers it as an approach to the study of the mind that tries to form learning and cognition in the shape of networks of neuron-like units. Empiricists emergentists believe that language learning is not dissimilar to other types of learning. They totally ignore the role of UG. This approach is sometimes called input based approach. As it was mentioned at the outset of the paper, the main focus here is on empiricist (mainstream) Emergentism.

\subsection{Emergentism and language acquisition}

As a matter of fact, the roots of the emergentist approach to language acquisition can be traced to Piaget (1954), whose theory of development emphasized the interaction between experience and general cognitive mechanisms. This is sometime referred to as developmental Emergentism (MacWhinney, 2002, cited in O' Grady, 2003). O' Grady (2003) astutely mentions that much current emergentist research is related to the notion that language acquisition can be concentrated on the application of simple learning mechanisms to pull out statistical regularities present in regular linguistic input. This position is sometimes referred to as a usage-based view of knowledge of language which is shaped in reaction to opportunities to infer utterances in the course of communication.

Furthermore, the emphasis in most emergentist work has been on a single property of this processor- its ability to recognize and calculate distributional events. This is mainly noticeable in the case of connectionist 
Mirzaee, S., \& Ghanizadeh, A.

modeling concerning Simple Recurrent Networks (e.g. Elman, 1999), which are specially designed to take note of local co-occurrence associations ( 'transitional probabilities').

\subsection{Chaos complexity theory}

Having presented a brief overview on Emergentism and its different types, let's have a brief look at chaos complexity theory and see what these two perspectives have in common regarding second language acquisition. According to Larsen-Freeman (1997), Chaos / complexity theory concerns with the behavior of dynamic systems, i.e., the systems which change in time. As Gleick (1987, p. 5) puts it, the study of chaos (the randomness generated by complex systems) is a study of process and becoming, rather than state and being. Dynamic systems move through space / time, following a path called an attractor, i.e., the state or pattern that a dynamic system is attracted to (Larsen-Freeman, 2000). Additionally, she claims that the main characteristics of dynamic systems are that all variables interact and this constant interaction keeps changing the system as a whole over time.

It has to be mentioned that Chaos / complexity theory focuses on complex systems. According to Larsen-Freeman (1997) and Ellis and Larsen-freeman (2006), systems are complex for two reasons. First, they often include a large number of components, and second, the behavior of complex systems is more than a product of the behavior of its individual components. In fact, the outcome of a complex system emerges from the interactions of its components; it is not built in any one component. As such, the interactions amongst the components in the system are the essential building blocks of the unpredictable structures that may emerge in the future.

\subsection{Complex nonlinear systems and language}

Larsen-Freeman (1997) took her idea a step further with giving an account of her study of the complex nonlinear systems and the study of language which have much in common. She believes that while language can be perceived as the aggregations of paradigmatic and syntagmatic units, it is also true that a view of language as a dynamic system is taken into account. The first widespread meaning of dynamic as applied to language is that of process- language which can be expressed as an aggregation of static units or products, but their use in actual speech involves an active process, typically referred to as parole or performance. The other common way that language is perceived to be dynamic is when it is dealt with as growth and change. Whilst meaning 'synchronic process' and 'diachronic change' to enlighten complex systems, dynamic has yet a third explanation i.e. dynamic as isomorphic process. It means that every time language is used, it is changed. Such a view proposes that language organizes itself in an organic way, as do other complex nonlinear systems (Larsen-Freeman, 1994).

These findings led Larsen Freeman to claim that as is true with other dynamic nonlinear systems, language is also complex. Since, both criteria of complexity are met: first, it consists of many different subsystems: phonology, morphology, lexicon, syntax, semantics, and pragmatics. Second, these subsystems are mutually dependent. It means that a change in one of them can cause change in others. In other words, the behavior of the whole came out of the interaction of the subsystems.

\subsection{Complex nonlinear systems and second language acquisition}

Larsen-Freeman (1997) contends that SLA process is also known to be complex. In fact, there are many factors interacting with each other that verify the trajectory (PATH) of the developing IL. These factors can be: the source language, the target language, the markedness of the L1 and L2, the amount and the type of input, the amount and the type interaction; besides these, factors like age, aptitude and socio-psychological factors are at the play.

Additionally, it is beneficial to mention that learning linguistic items is not a linear process. It means learners do not need to master one item at a time and then move ahead to another. In fact, the learning curve for a 
On the legitimacy of Emergentism and Chaos complexity theory

single item is not linear either. Considering the system as open one, and considering it as continued input, it can be concluded that the inter-language system is self-organizing (Larsen-freeman, 1994).

\section{Implication of chaos complex theory in SLA research}

Taken together, the above discussion puts forward the potential contributions of chaos/complexity theory in explaining various aspects of language and language acquisition. It appears that there are sufficient reasons to take a closer look at language learning from a complex chaotic systems theory perspective. Cameron (1999) implementing chaos complexity theory in the use of tasks in language teaching concluded that:

The constructs and tools of complex systems theory offer new possibilities for theorizing and researching classroom language use and learning. Tasks or activities carried out in the contingencies of real classroom contexts are more fruitfully investigated, not as a static background to performance, but as dynamic-changing and evolving in use-and, at the same time, constructing and constraining individual performance and learning (p.1).

As Finch (2001) points out, the language classroom along with teachers and students constructs a complex system in which events do not occur in a linear causal fashion, but in which a number of forces interact in complex, self-organizing ways, creating changes that are partly predictable and partly unpredictable. In this system, events which may seem unimportant on the face of it can build up to critical thresholds, stimulating sudden, irreversible shifts and new structures (Finch, 2004). Applying the notions of chaos complexity to language learning can have a number of consequences for the way in which we view 'learning'. Van Lier (2004) notes that within a complex system, a large number of influences are present in a partially chaotic unpredictable manner and among all the interaction, a complex order emerges. This dynamic order provides affordance for active participants in the setting, and learning emerging as part of affordances is picked up and exploited for further action. Adopting a chaos complexity model of language learning will entail several critical adjustments in language education:

\subsection{Underlining complementarity, inclusiveness, and interface of various views on language learning and}

language learners.

As Larsen-Freeman (1997) contended language learning literature is depleted with diverse dichotomies, such as input/output, innatism/constructivism, competence/performance, process/product, individual speaker-hearer/social interaction, etc. Chaos complexity theory proposes that we need to perceive "SLA as both/and rather than either/or" (Larsen-Freeman, 1997, p. 158). This implies that these categories might be false dichotomies; thus, chaos complexity theory advocates obscuring the boundaries in SLA- to perceive complementarity, and to practice inclusiveness rather than exclusiveness and disagreement.

\subsection{Underlining individualized learning and individual differences.}

Given that a basic tenet of chaos complexity theory is that any learning experiences is unpredictable and involves the interaction of a host of factors, no single and standardized one-size-fits-all pedagogy could be prescribed for language learning. Therefore, educationalists should take into account individual differences in devising instructional materials and activities. They should attempt at making available an input-rich environment combined with diverse and engaging activities that enhance individual learning. Language learning is too complex to be captured in an inclusive prescription which is not tailored to individual needs. All learning and teaching approaches and methods from inductive to deductive approaches, from drill-based to task-based activities, from communicative-derived methods to grammar-based methodologies should be appreciated. This approach simply acknowledges that students learn at different rates and in different ways and allows learners to work at their own speed, making learning achievements appropriate to their current status. As Harshbarger (2007) puts it, 
Mirzaee, S., \& Ghanizadeh, A.

Learning and learners are not amenable to a best method, a best book, a best test, or a best curriculum. Learners are most amenable to influences that recognize, respond to, and nurture their truly complex and dynamic learning processes (p.29).

\subsection{Underlining process - based and holistic assessment approaches}

Chaos complexity models of language education have important implications for language assessment. As an important effect, a shift is expected from product (what was learned) to process (how it was learned). It is also conceivable to see more emphasis on self-assessment which can foster other important skills, such as reflection, critical thinking and self-awareness - as well as giving students insight into the assessment process. Under the influence of chaos complexity theory, educators are also expected to take a more holistic stance in assessing language learners. They should not confine themselves to linguistic aspects but they need to appraise linguistic, affective, and social skills.

\section{Concluding remarks}

\subsection{A challenge with nativist paradigm}

What comes in this part is bringing some pieces of evidence considering empiricist emergentists' view point against nativists paradigm in language learning. Gregg (2003) is regarded as one of the advocates of UG. Based on Eubank and Gregg (1995, p. 51), UG “is the only theory that there is". Gregg highlights that UG is based on two main features:

$>\quad$ linguistic competence constitutes a separate module of the mind, and

$>\quad$ learners must possess innate knowledge of linguistic facts because these facts are not discoverable from the input.

As it is rightfully argued by Ellis (1998), Emergentism is an apparent challenge to Gregg (2003) since it disputes both aforementioned premises. In fact, Emergentism views language learning like all other kinds of learning. More importantly, it considers environment as the immense and complex competent of enabling learners to provoke facts. The argument is that emergentists theories are used in contradiction of UG paradigm of acquisition in some parts.

As mentioned at the outset of this part and in line with Ellis (2008), Emergentism put emphasis on the interaction between organism and environment and refuted the continuation of pre-determined, domain specific faculties as argued by UG proponents. Moreover, as it is suggested by O' Grady (2003), a unifying idea of emergentist work is the refutation of innate grammatical principles supporting more general mechanisms of cognition and learning.

In the field of language acquisition, emergentists declare that simple learning mechanisms, of the kind demonstrated somewhere else in cognition, are sufficient to cause the emergence of complex language versions. In Ellis's words,

The complexity of language emerges from relatively simple developmental processes being exposed to a massive and complex environment (Ellis, 2008, p. 233).

It is worthy of note that according to Ellis (1988), Functional linguistics (Bates \& MacWhinney, 1981,1989), Connectionism (Elman et al., 1996) and Constructivist child language researchers (Tomasello, 1992) are in the same vein with emergentists' idea since they believe that language study's consideration of ontogenetic acquisition processes also believe in the complexity of the final result which stems from simple learning processes applied, overstretched periods of practice in the learner's lifetime, to the rich and complex 
problem-space of language evidence.

Consequently, based on all of these theorists a thorough understanding of language cannot come from one regulation alone. As Cook and Seidlhofer (1995) helpfully run through, language can be regarded as:

a genetic inheritance, a mathematical system, a social fact, the expression of individual identity, the expression of cultural identity, the outcome of a dialogic interaction, a social semiotic, the sum of attested data, a collection of memorized chunks, or electrical activation in a distributed network. . . We do not have to choose. Language can be all of these things at once (p. 4).

Emergentists and chaos/complexity scientists as Larsen-Freeman's (1997) claims be aware of language as all of these things at once, language at any one of these levels is in fact a result of interactions between language at all of these levels: The result is a dynamic, complex, non-linear system in which the timing of events can have remarkable control on the developmental course and outcomes.

Indeed, as Ellis (1998) contends, in emergentists point of view, the rules of UG have a parallel status - the regularities of generative grammar present well-researched patterns maintained by explanations. In fact, emergentists substitute a process description for a state description, look at development rather than the final position, and focus on the language acquisition process (LAP) more willingly than language acquisition device (LAD).

Emergentists suppose that the universals of language have emerged, just like the universals of human transport solutions have emerged (Ellis, 1998). As Simon (1983, as cited in Ellis, 1998, p. 644) believes:

Cars are cars all over the world. Yet, their universal properties have not come from some grand preordained design; rather they have arisen from the constraints imposed by human transport goals, society, physics, and the availability of natural resources.

Now it's time to take into consideration some pieces of evidence that can help us better understand the nature of this dispute between Emergentism and UG assumptions proposed by Chomsky (1965, 1981, \& 1986).

A. Modularization: It is claimed that language is a separate faculty of mind. But what happens if you cut one part of the brain from auditory cortex and paste it to visual cortex, it gets the visual properties. So the brain has the property of elasticity. It shows that here it is the matter of automaticity not innateness (Hopper, 1987).

B. Grammar: Additionally, Hopper (1987) believes that grammar is not fixed: there is a movement. In fact, Chomsky believes in revolution of language, while Hopper believes in evolution of language that is the language of human being is the continuation of animal language.

C. Poverty of stimulus: It has also been found that the interaction between child and mother is rich enough to acquire the language. However, Chomsky believes that because learners converge on the same grammar in broadly similar patterns of acquisition even though language input is degenerate, variable and lacking in reliable negative evidence. Learnability arguments suggest that there must be strong constraints on the possible forms of grammars, the determination of which constitutes the enterprise of (UG);

D. Grammar is epiphenomenal to discourse: It means that this is discourse which determines grammar and in fact grammar is a byproduct of discourse. There are some issues involved here like the issue of transitivity, grounding, and prototype (Hopper, 1987).

What was mentioned above are some of the assumptions of UG proposed by Chomsky and their counter arguments by Anti Chomskian theorists which were discussed very briefly. 
Here we elaborate on one of these issues which can better explain the shortcomings of UG. The issue of proto-typicality which shows that being a verb when it implies action and being a noun when it implies thing is a matter that can be explained by UG but noun hood and verb hood are the results of discourse. These issues can be related to the notion of emergent grammar that meant to suggest that structure or regularity comes out of discourse and is shaped by discourse as much as it shapes discourse in an ongoing process. Grammar is not to be understood as prerequisite for discourse. Its forms are not fixed templates but are negotiable in face to face interaction in ways that reflect the individual speakers' past experience of these forms and their assessment of the present context (Hopper, 1987). He also mentions that Emmergent Grammar points to a grammar which is not abstractly formulated and represented, but always anchored in the specific concrete form of an utterance. Last but not least, Hopper in his article highlights the role of deliberate practice and believes in the human becoming who comes out of practice and prefers to face the music rather than human being who comes out of heredity and prefers to pass the buck.

The sheer truth is that the language learning falls at an exciting time in the history of language research that can shed more light on these UG assumptions (Elman, et al., 1996). What's more, it should be highlighted that based on the literature it is the assumptions of UG that are under attack, not the generative grammar descriptions of the relations between the linguistic units (O' Grady, 2003).

As Ellis (1998) puts it,

Many of the criticisms address generative linguistics' taking the uniquely human faculty of language and then studying it in isolation, divorced from semantics, the functions of language, and the other social, biological, experiential and cognitive aspects of humankind. This autism has two consequences. First, it concentrates the study of language on grammar, ignoring such areas as lexis, fluency, idiomaticity, pragmatics and discourse. Second, it dramatically restricts the potential findings of the study of grammar: If the investigation never looks outside of language, it can never identify any external influences on language (p. 633).

In addition, Neurobiologists and Emergentists believe that the nativist assumption of the language instinct hypothesis does not have any reasonable process clarification (Elman et al., 1996). In fact, existing theories of brain function, process and development do not willingly allow for the legacy of structures which might provide principles or parameters of UG. In the Emergentist viewpoint as Elman et al. (1996) point out, interactions occurring at all levels, from genes to environment, leading to the emergent forms and behavior. These outcomes may be exceedingly restrained and universal, but they are not themselves directly contained in the genes in any domain-specific way. Instead, human growth is under the regulatory control, where precise pathways to adulthood echo various interactions at the cellular level occurring during development.

In the same vein, MacWhinney (1998) has pointed out that nature is supplied with examples of this type of emergence, for instance, the hexagonal shape of cells in a honeycomb, the pattern of stripes on a tiger, the structuring of catalytic enzymes and fingerprints. So as mentioned previously, for emergentists, the rules of UG have a parallel status i.e. the regularities of generative grammar provide well-researched patterns in need of explanations. Moreover, Bod (1998, cited in Ellis, 2001) shows that any systematic constraints of the fragments appears to jeopardize the statistical dependencies that are required for forecasting the proper structure of a sentence. This demonstrates that the prolific units of natural language cannot be described in terms of a minimal set of rules, constraints or principles, but rather they necessitate to be described in terms of a large superfluous set of practiced structures but the behavior of the society of syntax is identified by the interactions of all of its members, if communities are removed or if new individuals join, so the ecology alters. This conclusion is also supported in L1 acquisition by the findings of Bates and Goodman (1997).

Finally, let us refer you to a quotation from Chomsky (1977) that

No discipline can concern itself in a productive way with the acquisition and utilization of a form 
of knowledge without being concerned with the nature of that system of knowledge (p. 43).

And let's see how Ellis (2001, p.46) reacts to this. He says:

True. But then so is the emergentist counter that one cannot properly understand something without knowing how it came about. Which brings us back to the previously mentioned sentence: Constructivist views of language acquisition hold that simple learning mechanisms operating in and across the human systems for perception, motor-action and cognition as they are exposed to language data as part of a communicatively-rich human social environment by an organism eager to exploit the functionality of language is enough to drive the emergence of complex language representations.

\section{References}

Cameron, L. (1999). The complex dynamics of language use on tasks. Paper presented at the British Association for Applied Linguistics Annual Meeting, University of Edinburgh, US.

Chomsky, N. (1965). Aspects of a theory of syntax. Cambridge: MIT Press.

Chomsky, N. (1977). Knowledge and responsibility. New York: Pantheon Books.

Chomsky, N. (1981). Lectures on government and binding. Dordrecht: Foris.

Chomsky, N. (1986). Knowledge of language. New York: Praeger.

Cook, G., \& Seidlhofer, B. (Eds.). (1995). Principles and practice in applied linguistics. Oxford: Oxford University Press.

Ellis, R. (2008). The study of second language acquisition. Oxford: OUP.

Ellis, N. C. (1998). Emergentism, connectionism and language learning. Language Learning, 48(4), 631-664. http://dx.doi.org/10.1111/0023-8333.00063

Ellis, N. C. (2001). Constructions, chunking, and connectionism: The emergence of second language structure. In C. J. Doughty \& M. H. Long (Eds.), Handbook of second language acquisition (pp. 63-103). Boston: Blackwell Publishing.

Ellis, N. C. (2002). Frequency effects in language processing: A review with implications for theories of implicit and explicit language acquisition. Studies in Second Language Acquisition, 24(2), 143-188. http://dx.doi.org/10.1017/S0272263102002024

Ellis, N. C. (2008). The dynamics of language use, language change, and first and second language acquisition. Modern Language Journal, 41(3), 232-249. http://dx.doi.org/10.1111/j.1540-4781.2008.00716.x

Ellis, N. C. \& Larsen-Freeman, D. (2006). Language emergence: Implications for applied linguistics-Introduction to the special issue. Applied Linguistics, 27(4), 558-589. http://dx.doi.org/10.1093/applin/aml028

Elman, J. L. (1999). The emergence of language: A conspiracy theory. In B. MacWhinney (Ed.), The emergence of language (pp. 1-27). New Jersey: Lawrence Earlbaum Associates.

Elman, J. L., Bates, E. A., Johnson. M. H., Karmiloff-Smith. A., Parisi. D., \& Plunkett. K. (1996). Rethinking innateness: A connectionist perspective on development. Cambridge: MIT Press.

Eubank, L. \& Gregg, K.R. (1995). Et in amygdala ego? UG, (S)LA and neurobiology. Studies in Second Language Acquisition, 17, 35-57. http://dx.doi.org/10.1017/S0272263100013747

Finch, A. E. (2001). Complexity in the language classroom. Secondary Education Research, 47, 105-40.

Finch, A. E. (2004). Complexity and systems theory: Implications for the EFL teacher/researcher. Journal of Asia TEFL, 1(2), 27-46.

Gleick, J. (1987). Chaos: Making a new science. New York: Penguin Books.

Gregg, K. R. (2003). The state of Emergentism in second language acquisition. Second Language Research, 19(2), 95-128. http://dx.doi.org/10.1191/0267658303sr213oa

Harshbarger, B. (2007). Chaos, complexity and language learning. ICU Language Research Bulletin, 22, $17-31$.

Hopper, P. (1987). Emergent grammar. Berkeley Linguistic Society, 13, 139-57.

Larsen-Freeman, D. (1997). Chaos complexity science and second language acquisition. Applied Linguistics, 
Mirzaee, S., \& Ghanizadeh, A.

18(2), 141-65. http://dx.doi.org/10.1093/applin/18.2.141

Larsen-Freeman, D. (2000). Second language acquisition and applied linguistics. In W. Grabe (Ed.), Applied linguistics as an emerging discipline, Annual Review of Applied Linguistics, 20, 165-81. http://dx.doi.org/10.1017/S026719050020010X

Long, M. (1996). The role of the linguistic environment in second language acquisition. In W. Ritchie \& T, Bhatia (Eds.), Handbook of second language acquisition (pp. 356-370). San Diego: American Press.

MacWhinney, B. (1998). Models of the emergence of language. Annual Review of Psychology, 49(1), 199-227. http://dx.doi.org/10.1146/annurev.psych.49.1.199

Norris, J. \& Ortega, L. (2003). Defining and measuring SLA in C. J. Doughty \& M. H. Long (Eds.), Handbook of second language acquisition (pp.717-761). Boston: Blackwell Publishing. http://dx.doi.org/10.1002/9780470756492.ch21

O'Grady, W. (2003). The radical middle nativism without universal grammar. In C. J. Doughty \& M. H. Long (Eds.), Handbook of second language acquisition (pp. 43-62). Boston: Blackwell Publishing. http://dx.doi.org/10.1002/9780470756492.ch3

O’Grady, W. (2008). Innateness, universal grammar, and Emergentism. Lingua,118(4),620-631. http://dx.doi.org/10.1016/j.lingua.2007.03.005

O'Grady, W., Lee, M., \& Kwak, H. Y. (2009). Emergentism and second language acquisition. In W. Ritchie \& T. Bhatia (Eds.), Handbook of second language acquisition (pp. 69-88). Bingley, UK: Emerald Press.

van Lier, L. (2004). The ecology and semiotics of language learning. Mass: Kluwer Academic Publishers. http://dx.doi.org/10.1007/1-4020-7912-5

White, L. (2003). Second language acquisition and universal grammar. Cambridge: Cambridge University Press. http://dx.doi.org/10.1017/CBO9780511815065 